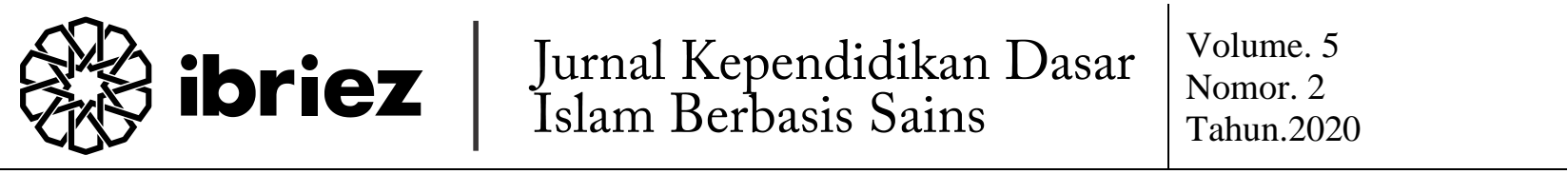

\section{Implementasi Corporate Social Responsibility (CSR) dalam Meningkatkan Mutu Kualitas Pendidikan SMK NU Banat Kudus}

\author{
Yassirli Amria Wilda*, Ahmad Sunoko** \\ ${ }^{*}$ Institut Agama Islam Negeri Kudus, ${ }^{* *}$ STAI Al-Anwar Sarang \\ Surel : yassirlywildan97@gmail.com
}

\begin{abstract}
Corporate Social Responsibility (CSR) is a form of corporate activity in managing business to produce a positive action on society to create a quality community. Corporate Social Responsibility (CSR) programs form education, sport, environment, and empowerment. Djarum Foundation is one of the companies that carry out corporate social responsibility activities in scholarship vocational programs. This program provides technical guidance to vocational high school (SMK) by teaching factory. Teaching Factory is a learning concept that combines theory with work practices to produce a product or service based on consumers' real orders. Teaching Factory is a learning form industrial condition to the school condition to make the quality industrial product. The method used in this research was qualitative research methods with data validity with the triangulation source. The theory of social contract and corporate social responsibility useful. One of the CSR programs education from Djarum Foundation is SMK NU Banat Kudus. SMK NU Banat Kudus is a vocational high school for special girls school with a significant Fashion Designer. Based on the research, the corporate social responsibility program education was implemented by Djarum Foundation. It provides benefits to SMK NU Banat Kudus. Furthermore, Djarum Foundation can give a scholarship to vocational high schools, which can increase quality education, from quality teachers, students, educational patterns curriculums, and producing industrial quality products.
\end{abstract}

Keywords: Corporate Social Responsibility, Djarum Foundation, Quality Education, Fashion Designer.

\section{Abstrak}

Corporate Social Responsibility (CSR) merupakan salah satu bentuk kegiatan perusahaan dalam mengelola bisnis untuk menghasilkan tindakan positif pada masyarakat untuk menciptakan komunitas yang berkualitas. Program Tanggung Jawab Sosial Perusahaan (CSR) berupa pendidikan, olahraga, lingkungan, dan pemberdayaan. Djarum Foundation merupakan salah satu perusahaan yang melaksanakan kegiatan tanggung jawab sosial perusahaan dalam program vokasi beasiswa. Program ini memberikan bimbingan teknis ke sekolah menengah kejuruan (SMK) dengan Teaching Factory. Teaching Factory merupakan konsep pembelajaran yang menggabungkan teori dengan praktek kerja untuk menghasilkan suatu produk atau jasa berdasarkan pesanan nyata konsumen. Teaching Factory merupakan bentuk pembelajaran kondisi industri terhadap kondisi sekolah untuk menghasilkan produk industri yang berkualitas. Metode yang digunakan dalam penelitian ini adalah metode penelitian kualitatif dengan keabsahan data dengan triangulasi sumber. 
Teori kontrak sosial dan tanggung jawab sosial perusahaan bermanfaat. Salah satu program CSR pendidikan dari Djarum Foundation adalah SMK NU Banat Kudus. SMK NU Banat Kudus merupakan Sekolah Menengah Kejuruan Khusus Putri Khusus Putri dengan Fashion Designer yang cukup signifikan. Berdasarkan penelitian tersebut, pendidikan program tanggung jawab sosial perusahaan dilaksanakan oleh Djarum Foundation. Ini memberikan manfaat bagi SMK NU Banat Kudus. Selanjutnya Djarum Foundation dapat memberikan beasiswa kepada SMK yang dapat meningkatkan kualitas pendidikan, mulai dari guru yang berkualitas, siswa, kurikulum pola pendidikan, dan menghasilkan produk yang berkualitas industri.

Kata kunci : Corporate Social Responsibility, Djarum Foundation, Pendidikan Berkualitas, Desain Fashion.

\section{PENDAHULUAN}

Indonesia merupakan salah satu negara berkembang yang sedang giat melaksanakan pembangunan. Perkembangan dan pembangunan di dunia industri semakin pesat. Hal tersebut menjadikan kawasan pemukiman penduduk dan sekolah tergusur oleh pembangunan industri. ${ }^{1}$ Kebijakan pembuatan kawasan industri dapat menimbulkan sisi positif dan negatif bagi lingkungan. Satu sisi, kawasan industri memberikan manfaat untuk meningkatkan taraf hidup dan kesejahteraan masyarakat dalam pertumbuhan ekonomi. Di sisi lain, dapat menimbulkan masalah baru yang sangat merugikan, seperti: global warming, pencemaran lingkungan, perubahan gaya hidup, radiasi serta munculnya berbagai penyakit mematikan akibat infeksi bahan kimia dari industrialisasi. ${ }^{2}$

\footnotetext{
${ }^{1}$ Siti Aminah, "Konflik Dan Kontestasi Penataan Ruang Kota Surabaya," MASYARAKAT: Jurnal Sosiologi 2, no. 1 (2015),

http://www.jke.feb.ui.ac.id/index.php/mjs/article/vie wArticle/4751.

${ }^{2}$ Udin Rinaldi, “ANALISIS CORPORATE SOCIAL RESPONSIBILITY PT TELKOMSEL AREA
}

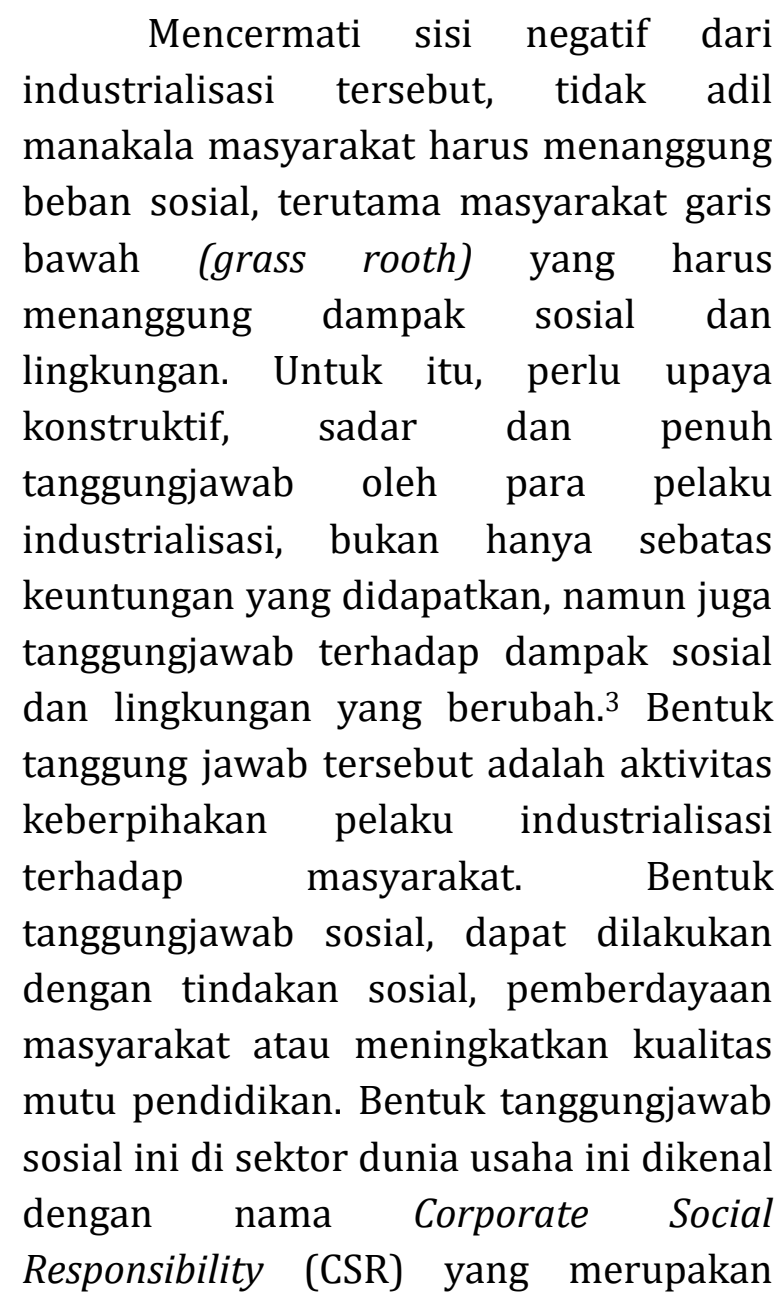

PONTIANAK DALAM UPAYA MENINGKATKAN CITRA PERUSAHAAN," Jurnal Ekonomi Integra 3, no. 1 (May 28, 2018): 001, https://doi.org/10.51195/iga.v3i1.102.

${ }^{3}$ Nurdizal M. Rachman, Asep Efendi, and Emir Wicaksana, Panduan Lengkap Perencanaan CSR (Jakarta: Penebar Swadaya, 2011). 
wujud kesadaran perusahaan sebagai upaya meningkatkan hubungan industrialisasi dengan masyarakat dan lingkungannya.

\section{Corporate Social Responsibility} (CSR) ini diatur secara tegas di Indonesia dalam Undang-Undang Nomer 25 Tahun 2007 tentang Penanaman Modal dan Undang-Undang Nomer 40 Tahun 2007 tentang Perseroan Terbatas terdapat pasal 74 ayat (1) menyatakan bahwa perseroan yang menjalankan kegiatan usahanya di bidang dan/atau berkaitan dengan sumber daya alam (SDA) wajib melaksanakan tanggungjawab sosial di lingkungan (CSR). ${ }^{4}$ Hal ini menunjukkan bahwa semua perusahaan pada hakikatnya diwajibkan untuk menerapkan Corporate Social Responsibility (CSR). Dan setiap perusahaan memiliki kewajiban menjalankan program Corporate Social Responsibility (CSR) dalam bidang pendidikan di wilayah perusahaan pada khususnya dan pendidikan di Indonesia pada umumnya.

Ada banyak perusahaan yang telah memiliki komitmen untuk melakukan CSR dan memilih bidang pendidikan sebagai salah satu fokus perhatiannya. ${ }^{5}$ Hal ini dikarenakan pendidikan merupakan hal yang terpenting untuk membangun suatu bangsa. Salah satunya, PT Djarum. Program CSR yang dilaksanakan oleh Djarum Foundation khususnya di bidang pendidikan adalah meningkatkan mutu

\footnotetext{
${ }^{4}$ Kemenkum HAM, "UNDANGUNDANGREPUBLIK INDONESIA NOMOR 40 TAHUN 2007 TENTANG PERSEROAN TERBATAS” (2007).

${ }^{5}$ Rimba Kusumadilaga, "PENGARUH CORPORATE SOCIAL TERHADAP NILAI DENGAN PROFITABILITAS
}

kualitas pendidikan Sekolah Menengah Kejuruan (SMK). Program ini merupakan kerjasama dengan Dinas Pendidikan, Pemuda dan Olah Raga Kabupaten Kudus yang telah ada sejak tahun 2012. Program ini diharapkan dapat meningkatkan kualitas lulusan SMK, sehinggat mereka dapat cepat terserap dan berhasil di dunia usaha, selain itu juga untuk meningkatkan minat lulusan SLTP/SMP sederajat agar memilih Sekolah Menengah Kejuruan sebagai bagian dari kelanjutan studi mereka. ${ }^{6}$

Salah satu sekolah yang bekerja sama dengan CSR Djarum foundation adalah SMK NU Banat Kudus di bidang Fashion Designer. SMK NU Banat Kudus merupakan sekolah khusus perempuan dengan program jurusan Fashion Designer. Tujuannya yaitu tidak hanya menjadi sumber daya manusia (perempuan) yang beraktivitas di rumah saja, tetapi juga menyiapkan sumber daya manusia lokal, khususnya perempuan, yang handal, terampil dan profesional sehingga siap bekerja di berbagai perusahaan dan menciptakan manusia mandiri yang mampu merintis usaha sendiri dengan kualitas produk layaknya hasil industri. Dengan begitu, kegiatan CSR Djarum Foundation dengan SMK NU Banat ini dapat meningkatkan kualitas mutu pendidikan, memiliki guru yang berkualitas, peserta didik yang mampu mengembangkan potensinya, kurikulum

\footnotetext{
VARIABEL MODERATING(Studi Empiris Pada Perusahaan Manufaktur Yang Terdaftar Di Bursa Efek)" (UNDIP, 2010).

6 "Djarum Beasiswa Plus," accessed January 23, 2021, https://djarumbeasiswaplus.org/.
} 
yang berkualitas hingga dapat menghasilkan produk yang berkualitas layaknya produk hasil industri. Berdasarkan uraian tersebut, maka tujuan yang ingin dicapai dalam penelitian ini adalah untuk mengetahui Implementasi Corporate Social Responsibility (CSR) Djarum Foundation dalam meningkatkan mutu kualitas pendidikan di SMK NU Banat Kudus.

\section{KAJIAN TEORI}

\section{Pengertian Corporate Social Responsibility (CSR)}

Corporate Social Responsibility (CSR) merupakan komitmen perusahaan atau dunia bisnis untuk berkontribusi dalam pengembangan ekonomi yang berkelanjutan dengan memperhatikan tanggungjawab sosial perusahaan dan menitikberatkan pada keseimbangan antara perhatian terhadap aspek ekonomis, sosial dan lingkungan. ${ }^{7}$

Banyak ahli yang belum memiliki kesamaan dalam memberikan definisi, tetpai sudh memiliki banyak sesnsi. Diantaranya adalah definisi yang dikemukakan oleh Maignan and Farrell yang mendefinisikan CSR sebagai:

"A business acts in socially responsible manner when its decision and actions account for and

\footnotetext{
${ }^{7}$ Hendrik Budi Untung, Corporate Social Responsibility (CSR) (Jakarta: Sinar Grafika, 2007), 1.

${ }^{8}$ Dwi Triyanto, "Pelaksanaan Corporate Social Responsibility (CSR) Di Bidang Pendidikan PT. Hino Motors Sales Indonesia (PT.HMSI)" (Universitas Negeri Yogyakarta, 2013), 4.
}

calance diverse stakeholder interst".8

Definisi ini menekankan perlunya memberikan perhatian seimbang terhadap kepentingan berbagai stakeholder yang beragam dalam setiap keputusan dan tindakan yang diambil oleh para pelaku bisnis melalui perilaku secara sosial dan bertanggung jawab.

Menurut Jhonson and Jhonson menjelaskan :

"Corporate Social Responsibility
(CSR) is about how companies
manage the business processes to
produce an overall positive impact
on society". 9
Definisi tersebut lebih menjelaskan bagaimana cara mengelola perusahaan baik sebagian maupun keseluruhan memiliki dampak positif bagi dirinya dan lingkungan. Untuk itu, perusahaan harus mampu mengelola bisnis operasinya dengan menghasilkan produk yang berorientasi secara positif terhadap masyarakat dan lingkungan.

Sedangkan menurut Lord Holme and Richard Watts mendefinisikan

"Corporate Social Responsibility is the continuing commitment by bussiness to behave ethically and contribute to economic develpoment while improving the equality of life

\footnotetext{
${ }^{9}$ Brigitte-Jane Ryan et al., "The 'Hearing Aid Effect' in Northern Territory Indigenous Australian Children as Perceived by Their Peers," Australian and New Zealand Journal of Audiology 28, no. 2 (2006): 55-74, https://search.informit.org/doi/10.3316/INFORMIT. 813719894564356.
} 
of the workforce and their families as well as of the local community and society at large".10

\section{Definisi diatas mengandung} makna, bahwa tanggungjawab sosial merupakan komitmen berkelanjutan para pelaku bisnis untuk memegang teguh pada etika bisnis dalam beroperasi, memberi kontribusi terhadap pembangunan berkelanjutan, serta berusaha mendukung peningkatan taraf hidup dan kesejahteraan bagi para pekerja, termasuk meningkatkan kualitas hidup masyarakat sekitar. ${ }^{11}$ Esensinya, arti komitmen berkelanjutan menunjukkan bahwa peruhasaan harus mampu mewujudkan kondisi bisnis dalam eksploitasi secara seimbang, dan menjaga komitmen dampak positif secara prefentif dan secara represif terhadap dampak negatif dari eksistensi dan strategi kebijakan perusahaan.

Dari semua definsi CSR tersebut, dapat disimpulkan bahwa CSR adalah komitmen perusahaan yang secara etis untuk mengintegrasikan kegiatan bisnisnya serta melaksanakan CSR secara berkelanjutan dengan memperhatikan stakeholder yang terkait dengan perusahaan dan lingkungan. Tujuannya adalah agar perusahaan, masyarakat termasuk karyawan, konsumen, komunitas lokal, investor, kreditor dan lingkungan bisa hidup berdampingan. CSR merupakan komitemen dunia bisnis untuk

\footnotetext{
${ }^{10}$ Alexander Dahlsrud, "How Corporate Social Responsibility Is Defined: An Analysis of 37 Definitions," Corporate Social Responsibility and Environmental Management 15, no. 1 (January 1, 2008): 1-13, https://doi.org/10.1002/csr.132.
}

memberi kontribusi terhadap pembangunan ekonomi berkelanjutan melalui kerjasama dengan stakeholder untuk meningkatkan kehidupan mereka melalui cara-cara yang baik bagi bisnis maupun pembangunan.

\section{Manfaat Corporate Social Responsibility (CSR)}

Keberadaan perusahaan harus bermanfaat untuk masyarakat sekitar. Artinya, prinsip dasar Corporate Social Responsibility (CSR) adalah pemberdayaan masyarakat setempat yang bertujuan untuk mengkreasikan masyarakat mandiri. Selain dari pemberdayaan masyarakat, dari sisi perusahaan agar operasional perusahaan berjalan lancar tanpa ada gangguan. Jika ada hubungan masyarakat dengan perusahaan tidak baik, bisa dipastikan ada masalah. Hal ini disebabkan karena kurang/miniminya perhatian perusahaan terhadap pelaksanaan CSR. Hal ini, menjelaskan bahwa perusahaan yang melaksanakan Corporate Social Responsibility (CSR) memiliki beberapa manfaat bagi perusahaan, antara lain ${ }^{12}$ :
a. Mempertahankan dan mendongkrak reputasi serta citra merek perusahaan;
b. Mendapatkan lisensi untuk beroperasi secara sosial;
c. Mereduksi risiko bisnis perusahaan;
d. Melebarkan akses sumber daya bagi operasional usaha;

\footnotetext{
${ }^{11}$ Nor Hadi, Corporate Social Responsibility (Yogyakarta: Graha Ilmu, 2011), 46.

${ }^{12}$ Untung, Corporate Social Responsibility (CSR), 67.
} 
e. Membuka peluang pasar yang lebih luas;

f. Mereduksi biaya, misalnya terkait dampak pembuangan limbah;

g. Memperbaiki hubungan dengan stakeholder;

h. Memperbaiki hubungan dengan regulator;

i. Meningkatkan semangat dan produktivitas karyawan;

j. Peluang mendapatkan penghargaan.

Praktik Corporate Social Responsibility (CSR) dapat meningkatkan reputasi dan mendukung bisnis perusahaan. Corporate Social Responsibility (CSR) tidak memberikan dampak ekonomis secara langsung dalam jangka pendek melainkan dalam jangka panjang. ${ }^{13}$ Pada hakikatnya Corporate Social Responsibility (CSR) adalah investasi bisnis dan dapat digolongkan ke dalam investment center. Hal ini mengindikasikan bahwa perusahaan sedang melakukan investasi sosial melalui program Corporate Social Responsibility (CSR), sehingga dapat berdampak terhadap kelancaran operasi perusahaan yang bersangkutan.

\section{Implementasi Corporate Social Responsibility (CSR)}

Implementasi Program CSR pendidikan ini disesuaikan dengan visi dan misi pemerintah untuk mewujudkan daya saing dan siap menghadapai kompetisisi arus globalisasi. Maka dari itu, ada tiga tahapan yang perlu dilakukan dalam mengaplikasikan CSR bidang

\footnotetext{
${ }^{13}$ T Romi Marnelly, "CORPORATE SOCIAL RESPONSIBILITY (CSR): Tinjauan Teori Dan Praktek Di Indonesia," Jurnal Aplikasi Bisnis 2, no. 2 (2012): 4959.
}

pendidikan ini, yaitu: Perencanaan, Implementasi dan Evaluasi. ${ }^{14}$

Pertama,

Perencanaan.

Perencanaan CSR pendidikan perlu memperhatikan sembilan hal dalam menentukan strategi yang lebih efektif:

a. Menetapkan visi sebagai landasan filososfis sebagai arahan bagi para pihak pengelola perusahaan untuk menentukan code of conduct agar sejalan dengan nilai masyarakat di lingkungannya.

b. Menetapkan misi sebagai penjabaran operasioanal dari visi yang telah ditentukan.

c. Menetapkan tujuan sebagai rumusan apa yang akan diselesaikan oleh perusahaan dalam keberpihakan terhadap pemangku kepentingan, kapan diselesaikan, serta mengukur secara akurat kegiatan dilakukan.

d. Menetapkan target sebagai batas dan acuan kecapaian pekerjaan jangka pendek dari tujuan yang telah ditentukan.

e. Mempertimbangkan kebiakan sebagai arah atau acuan dasar yang diambil pimpinan dalam merumuskan strategi pelaksanaan CSR.

f. Menetapkan strategi sebagai sarana untuk menjabarkan, visi, misi, tujuan, target, dan kebijakan tanggungjawab sosial yang akan dipraktikkan.

g. Merancang struktur organisasi, perlu dibentuk suatu departemen yang

\footnotetext{
${ }^{14}$ Wahyu Sulfemi, Manajemen Pendidikan Berbasis Multi Budaya (Bogor: STKIP Muhammadiyah Bogor, 2019).
} 
secara khusus bertanggung jawab atas pelaksanaan CSR.

h. Merancang Program sebagai bentuk aktivitas dan keefektifan terhadap kemanfaat pada stakeholder dan lingkungan.

i. Menyediakan sumber daya manusia merupakan pihak karyawan yang diserahi pelaksanaan aktivitas tanggungjawab sosial.

Implementasi CSR ini dapat dilaksanakan secara self managing, berarti implementasi CSR yang perusahaan melaksanakan sendiri di lapangan, dengan membentuk departement atau yayasan dalam melaksanakan CSR. Atau dilaksanakan secara outsourcing yang berarti pelaksanaan CSR diserahkan pada pihak ketiga, sehingga perusahaan tidak terlibat angsung dalam pelaksanaan di lapangan.

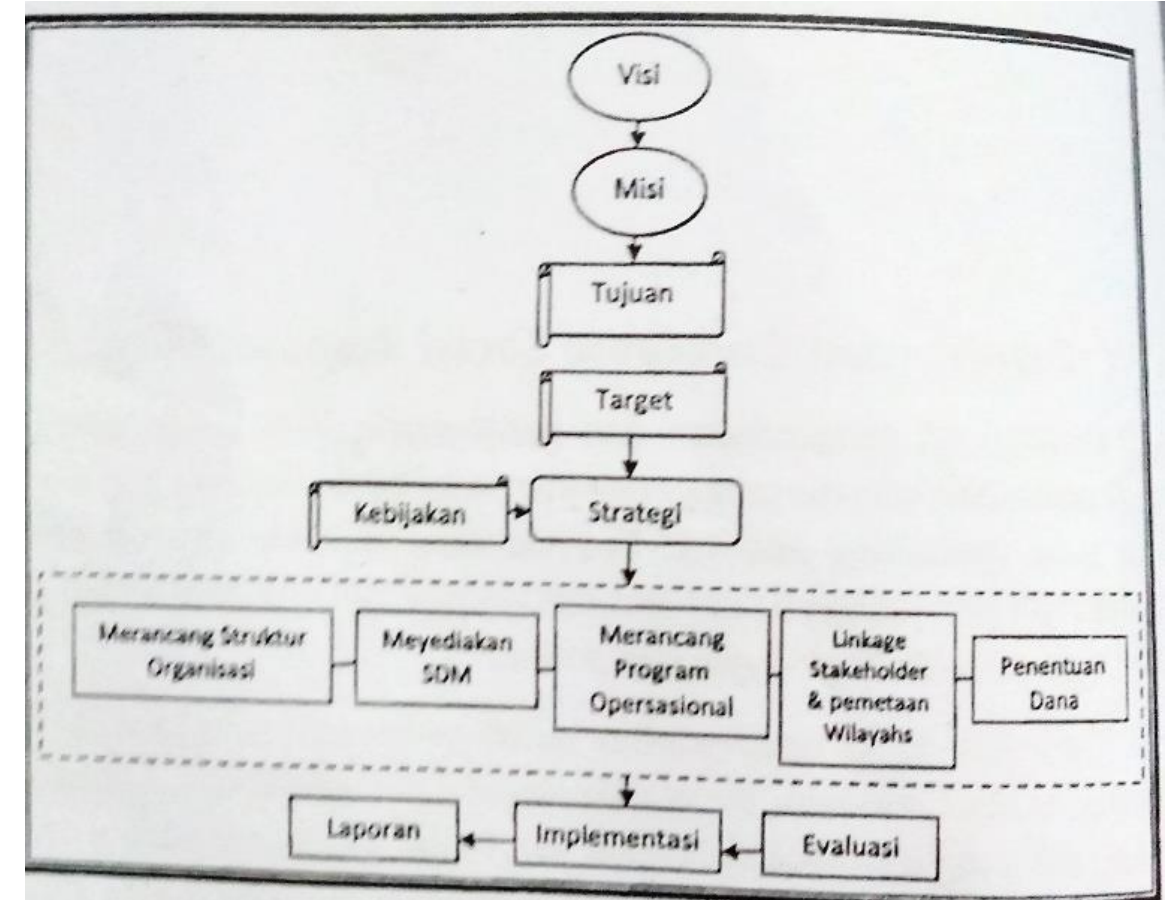

Gambar 1. Gradasi Implementasi CSR

Kedua, Implementasi.

Implementasi CSR berarti merencanakan implementasi pelaksanaan CSR di lapangan. Tahapan ini merupakan tahap aplikasi program CSR sebagaiama telah direncakan sebelumnya. Penerapan CSR ini membutuhkan iklim organisasi yang saling percaya dan kondusif, sehingga memunculkan motivasi dan komitmen pelaksanan.implementasi CSR ini memiliki tiga strategi utama, yakni sentralisasi, desentralisasi dan kombinasi.
Ketiga, Evaluasi. Suatu program, CSR membutuhkan pemantauan dan evaluasi dalam rangka perbaikan di masa depan, sekaligus menentukan tingkat capaian kinerja aktivitas sosial yang telah ditentukan. Evaluasi ini ditujukan untuk mengetahui sejauhmana pencapaian tujuan program serta apakah terdapat penyimpangan yang membutuhkan tindakan koreksi. Dilihat dari horizon waktu, evaluasi CSR dapat dilakukan harian, mingguan, bulanan, triwulan, 
semesteran maupun tahunan. Dilihat dari proses pelaksanaan evaluasi, dapat dilakukan ketika masih pada proses perencanaan, saat pelaksanaan program setelah selesai program. Sedangkan untuk melihat dan menentukan tingkat keberhasilan perlu disusun standar evaluasi dan keberhasilan program. ${ }^{15}$

Menurut Princes of Wales Foundation ada lima hal penting yang dapat mempengaruhi implementasi CSR: Pertama, menyangkut human capital atau pemberdayaan manusia. Kedua, environments yang berbicara tentang lingkungan. Ketiga, Good Corporate Governance, artinya mekanisme bagaimana sumber daya perusahaan dialokasikan menurut aturan hak dan kuasa. Keempat, Social Cohesion, artinya dalam melaksanakan CSR jangan sampai menimbulkan kecemburuan sosial. Kelima, Economic Strenght, atau memberdayakan lingkungan menuju kemandirian di bidang ekonomi. Selain itu, faktor lainnya yang mempengaruhi implementasi CSR adalah komitmen pimpinan perusahaan, ukuran dan kematangan perusahaan serta regulasi dan sistem perpajakan yang diatur pemerintah. ${ }^{16}$

\section{Pendidikan}

Menurut Undang-undang No. 20 Tahun 2003 tentang Sistem Pendidikan Nasional pasal 1 Ayat (1), Pendidikan adalah usaha sadar dan terencana untuk mewujudkan suasana belajar dan proses

\footnotetext{
${ }^{15}$ Hadi, Corporate Social Responsibility, 141.

${ }^{16}$ Untung, Corporate Social Responsibility (CSR), 12.
}

pembelajaran agar peserta didik secara aktif mengembangkan potensi dirinya untuk memiliki kekuatan spiritual keagamaan, pengendaian diri, kepribadian, kecerdasan, akhlak mulia, serta ketrampilan yang diperlukan dirinya, masyarakat, bangsa dan negara. Sejumlah perusahaan menetapkan kebijakan bahwa pendidikan merupakan prioritas Corporate Social Responsibility (CSR). ${ }^{17}$

Pendidikan perlu menjadi prioritas dalam pembangunan bangsa, khususnya dalam meningkatkan kualitas sumber daya manusia (SDM). Adanya CSR pada dunia pendidikan merupakan salah satu gerakan bersama secara nasional yang perlu dilakukan sebagai solusi alternatif di tengah perkembangan di Indonesia. Berbagai implementasi CSR melalui kegiatan pemberian beasiswa, pelaksanaan pelatihan maupun memberikan kesempatan magang oleh berbagai perusahaan dan menjadikan peran pendidikan akan semakin besar dalam pengembangan masyarakat. Artinya, CSR dalam meningkatkan mutu kualitas pendidikan menyangkut input, proses dan output pendidikan. Mutu mengacu pada prestasi atau hasil pendidikan. Kepekaan perusahaan terhadap dunia pendidikan inilah merupakan investasi yang dapat meningkatkan kualitas mutu pendidikan serta dapat memberikan manfaat secara berkesinambungan dan keberlanjutan.

\footnotetext{
${ }^{17}$ Megawati (presiden Republik Indonesia) Sukarnoputri, "Undang-Undang Nomor 20 Tahun 2003 Tentang Sistem Pendidikan Nasional," Pub. L. No. UU No 2 Tahun 2003 (2003).
} 


\section{METODE PENELITIAN}

Dalam penelitian ini, metode yang digunakan adalah metodologi penelitian kualitatif, dimana penelitian lebih menekankan pada proses-proses dan makna makna yang tidak diukur secara jumlah, angka atau frekuensi. Dengan menggunakan metodologi kualitatif, penulis akan mendapatkan data dan informasi yang akurasinya dapat terjamin. Pengumpulan data dilakukan dengan triangulasi yakni dengan pengamatan atau observasi, telaah wawancara dan sistem dokumentasi yang dilakukan pada waktu tertentu dan tempat di SMK NU Banat Kudus. Teknik triangulasi yang dilakukan dalam penelitian ini adalah triangulasi sumber dengan cara kerja mengecek data yang diperoleh dari beberapa sumber, data dideskripsikan dikategorisasikan kemudian dianalisis oleh peneliti untuk menghasilkan suatu kesimpulan yang dicocokkan dengan dominan lapangan. ${ }^{18}$ Teknik analisis data yang digunakan dengan aktifitas reduksi data, penyajian data, mengambil keputusan dan verifikasi. ${ }^{19}$ Implementasi yang dimaksud adalah keefektifan program CSR pendidikan dari Djarum Foundation terhadap kualitas mutu pendidikan, sehingga pada penelitian ini akan dimulai dari perencanaan, implementasi dan evaulasi dari dampaknya pelaksanaan CSR pendidikan di SMK NU Banat Kudus.

\footnotetext{
${ }^{18}$ Sugiyono, Metode Penelitian Pendidikan (Pendekatan Kuantitatif, Kualitatif, Dan R\&D) (Bandung: Alfabeta, 2013), 373.
}

\section{HASIL PENELITIAN DAN PEMBAHASAN}

Pada bab ini dibahas mengenai hasil penelitian dan pembahasan implementasi program CSR pendidikan dari Djarum Foundation, fokusnya pada peningkatan mutu kualitas pendidikan Sekolah Menengah Kejuruan (SMK) di SMK NU Banat Kudus. Implementsi ini sesuai dengan program perusahaan yang memiliki komitmen terhadap dunia pendidikan, membangun dan meningkatkan fasilitas pendidikan, mendukung penyelenggaraan pendidikan, memberikan pelatihan kepada siswa, memberikan beasiswa serta mengadakan riset ataupun karya tulis.

Program CSR Djarum Foundation pada SMK NU Banat Kudus ini meliputi perencanaan, implementasi dan evaluasi. Perencanaan CSR djarum Forundation di SMK NU banat Kudus di bidang Fashion Designer ini meliputi perencanaan peserta didik, perencanaan pendidikan, perencanaan tenaga kependidikan, perencanaan sarana dan prasarana pendidikan, perencanaan kurikulum dan pembelajaran. Dari perencanaan diatas, perencanaan kurikulum yang lebih spesifik dapat menjelaskan kualitas mutu pendidikan di SMK NU Banat Kudus. Kurikulum yang digunakan adalah Teaching Factory sebagai patokan dalam mengoptimalkan perkembangan peserta didik, pengalaman belajar yang diperoleh peserta didik berkat arahan, bimbingan dan dapat dipertanggungjawabkan oleh sekolah. Teaching Factory ini dimana

\footnotetext{
${ }^{19}$ Sugiyono, 335.
} 
proses pembelajaran berbasis industri, produk dari hasil proses pembelajaran dikonsep untuk berdayajual dan siap dipasarkan. Selain itu kurikulum yang digunakan SMK NU banat Kudus menggunakan kurikulum 2013, yang diharapkan peserta didik mengikuti kegiatan belajar mengajar tidak hanya mendapatkan teori saja tetapi juga mempraktikkan teori yang didapat. Artinya, dengan perpaduan kurikulum 2013 dan pembelajaran berbasis Teaching Factory ini, dapat membantu lulusan peserta didik dalam memperoleh kesempatan kerja yang lebih baik.

Implementasi CSR Djarum Foundation dalam meningkatkan kualitas mutu pendidikan SMK NU Banat Kudus menggunakan kurikulum 2013 dan pembelajaran berbasis Teaching Factory. Kurikulum 2013 ini menekankan pada kesiapan peserta didik untuk bekerja sesuai bakat dan minat, keseimbangan antara hard skill dan soft skill, pengamatan dan pengalaman di lapangan sangat diperlukan. Faktor lingkungan budaya juga mempengaruhi cara berpikir, bertindak dan berwawasan yang menempatkan kepentingan umum diatas kepentingan sendiri.

Sedangkan penerapan Teaching Factory ini memadukan konsep bisnis dan pendidikan kejuruan sesuai dengan kejuruan di SMK NU Banat Kudus di bidang Fashion Designer. Dalam pembelajaran Teaching Factory ada istilah C1, C2, C3 untuk peringkasan materi. Artinya, C1 adalah materi yang diberikan kepada peserta didik kelas $\mathrm{X}$, meliputi: pembelajaran kewirausahaan, ciri-ciri kewirausahaan, sikap kewirausahaan, membuat proposal usaha dan segala sesuatu yang berkaitan dengan wirausaha. C2 adalah materi yang diberikan kepada peserta didik kelas XI, meliputi: eksperimen membuat karya sesuai dengan bidangnya, artinya peserta didik dibebaskan untuk membuat pola, mendesain baju dan memotong kain sesuai dengan bidangnya dengan arahan dari guru sebagai pendamping, konsultan, asesor dan fasilitator. C3 adalah materi yang diberikan kepada peserta didik kelas $\mathrm{X}$, meliputi: mempraktikkan pembelajaran C1 dan C2 dengan pemarasan produk dan jasa yang dibuat oleh peserta didik atau unit produksinya. ${ }^{20}$

Dalam pelaksanaanya, di SMK NU Banat Kudus ini menekankan untuk pengembangan soft sklill dalam pembuatan busana muslim dan selalu mengangkat unsur budaya sekitar. Artinya, dalam pembuatan baju lebih ke ready to wear yang nyaman tapi tetep modis yang bisa dipakai buat muslimah atau non hijab dengan tetap melestarikan dan mengembangkan khas daerah atau batik dan tenun khas Indonesia. Sehingga, proses pembelajaran di SMK NU Banat kudus ini dapat diselenggarakan secara interaktif, inspiratif, menyenangkan, menantang, memotivasi peserta didik untuk berpartisipasi aktif, serta memberikan ruang yang cukup bagi prakarsa, kreatifitas, dan kemandirian

\footnotetext{
${ }^{20}$ Agung Kuswantoro, Teaching Factory

(Yogyakarta: Graha Ilmu, 2014), 69.
} 
sesuai bakat dan minat, perkembangan fisik, dan psikologi peserta didik. ${ }^{21}$

Tidak hanya itu, adanya CSR Djarum Foundation dan Zelmira, SMK NU Banat Kudus juga memperhatikan dalam pengenalan ilmu wirausaha kepada peserta didik. Artinya, peserta didik diberitahu cara berjualan atau memanfaatkan sosail media dalam penjualan dan menjalin kerjasama wirausaha dalam perekrutan alumni di dunia industri, sehingga SMK bisa menerapkan program pinjaman mesin jahit kepada lulusan yang memerluka, untuk selanjutnya merekan akan megangsur untuk melunasi mesin yang mereka pinjam untuk melanjutkan usahanya. Dengan begitu, tidak akan ditemui lulusan yang tidak berkesempatan membuka lapangan pekerjaan karena terkendala arana prasarana.

Adanya bantuan CSR Djarum juga menjadikan SMK NU Banat Kudus mendapatkan kategori sekolah kreatif, dengan adanya produksi setiap hari oleh peserta didik, sekolah juga menyediakan ruangan khusus untuk menegrjakan tugas, sejumlah studio design dengan peralatan canggih juga sudah disipakan, seperti perangkat komputer optitex fashion cat yakni piranti lunak yang umumnya digunakan perancang dapat membuat rancangan busana serta kurwa rupa dalam bentuk tiga dimensi yang bisa disesuaikan bentuk dan ukuran tubuh pemakai dengan sempurna. Dengan adanya lep dan studio ini, peserta didik dapat berkoordinasi, berdiskusi, presntasi, elaborasi,

\footnotetext{
21 Teguh Triwiyanto, Manajemen Kurikulum Dan Pembelajaran (Jakarta: Bumi Aksara, 2015), 173.
}

eksperimen dan berkepresi untuk mendapatkan ide-ide yang kreatif.

Evaluasi dari adanya kontribusi CSR Djarum Foundation, SMK NU Banat Kudus menjadi sekolah fashion pertama di Indonesia yang memiliki mutu kualitas pendidikan yang unggul dan mendapatkan sorotan dan pemerhati fashion. Dengan mengikuti berbagai kegiatan pameran, kompetensi di bidang fashion yang diselenggarakan dari tingkat nasional, maupun internasional, seperti Jakarta Fashion Week di Jakarta, Pameran Dayang Internasional di Hongkong, Orbit Compettion di Jakarta, dan sebagainya, SMK NU Banat Kudus mampu mengenalkan kepada masyarakat tentang konsep SMK jurusan Fashion Designer sebagai lembaga pendidikan yang tidak hanya mampu mencetak peserta didik menjadi tenaga jahit tetapii juga untuk menjadi Fashion Designer. SMK NU Banat Kudus ini mampu menunjukkan hasil pembelajaran yang berjalan sesuai dengan apa yang telah direncanakan, mampu meningkatkan kualitas mutu pendidikan dengan menjadi lulusan yang mampu meningkatkan kualitas hidup yang lebih baik demi terwujudnya bangsa yang kreatif, inovatif dan produktif dan dapat memajukan dunia ekonomi kreatif di Indonesia ke taraf Internasional.

\section{KESIMPULAN}

Berdasarkan hasil penelitian dan analisis data yang diperoleh, dapat disimpulkan bahwa implementasi CSR Djarum Foundation di SMK NU Banat 
Kudus di bidang Fashion Designer memiliki tiga tahapan. Pertama, perencanaan CSR djarum Forundation di SMK NU banat Kudus di bidang Fashion Designer ini meliputi perencanaan peserta didik, perencanaan pendidikan, perencanaan tenaga kependidikan, perencanaan sarana dan prasarana pendidikan, perencanaan kurikulum dan pembelajaran. Kedua, implementasi CSR Djarum Foundation dalam meningkatkan kualitas mutu pendidikan SMK NU Banat Kudus menggunakan kurikulum 2013 dan pembelajaran berbasis Teaching Factory. Kurikulum 2013 ini menekankan pada kesiapan peserta didik untuk bekerja sesuai bakat dan minat, keseimbangan antara hard skill dan soft skill, pengamatan dan pengalaman di lapangan sangat diperlukan. Sedangkan penerapan Teaching Factory ini memadukan konsep bisnis dan pendidikan kejuruan sesuai dengan kejuruan di SMK NU Banat Kudus di bidang Fashion Designer. Ketiga, Evaluasi dari adanya kontribusi CSR Djarum Foundation, SMK NU Banat Kudus menjadi sekolah fashion pertama di Indonesia yang memiliki mutu kualitas pendidikan yang unggul dan mendapatkan sorotan dan pemerhati fashion, dengan menjadi lulusan yang mampu meningkatkan kualitas hidup yang lebih baik demi terwujudnya bangsa yang kreatif, inovatif dan produktif dan dapat memajukan dunia ekonomi kreatif di Indonesia ke taraf Internasional.

\section{REFERENSI}

Aminah, Siti. "Konflik Dan Kontestasi Penataan Ruang Kota Surabaya."
MASYARAKAT: Jurnal Sosiologi 2, no.

1 (2015).

http://www.jke.feb.ui.ac.id/index.ph

$\mathrm{p} / \mathrm{mjs} /$ article/viewArticle/4751.

Dahlsrud, Alexander. "How Corporate

Social Responsibility Is Defined: An

Analysis of 37 Definitions." Corporate

Social Responsibility and

Environmental Management 15, no. 1

(January 1, 2008): 1-13.

https://doi.org/10.1002/csr.132.

“Djarum Beasiswa Plus." Accessed

January 23, 2021.

https://djarumbeasiswaplus.org/.

Hadi, Nor. Corporate Social Responsibility. Yogyakarta: Graha Ilmu, 2011.

HAM, Kemenkum. UNDANGUNDANGREPUBLIK INDONESIA NOMOR 40 TAHUN 2007 TENTANG PERSEROAN TERBATAS (2007).

Kusumadilaga, Rimba. "PENGARUH CORPORATE SOCIAL TERHADAP NILAI DENGAN PROFITABILITAS VARIABEL MODERATING(Studi Empiris Pada Perusahaan Manufaktur Yang Terdaftar Di Bursa Efek)." UNDIP, 2010.

Kuswantoro, Agung. Teaching Factory. Yogyakarta: Graha Ilmu, 2014.

Marnelly, T Romi. "CORPORATE SOCIAL RESPONSIBILITY (CSR): Tinjauan Teori Dan Praktek Di Indonesia." Jurnal Aplikasi Bisnis 2, no. 2 (2012): 49-59.

Nurdizal M. Rachman, Asep Efendi, and Emir Wicaksana. Panduan Lengkap Perencanaan CSR. Jakarta: Penebar Swadaya, 2011.

Rinaldi, Udin. "ANALISIS CORPORATE SOCIAL RESPONSIBILITY PT TELKOMSEL AREA PONTIANAK DALAM UPAYA MENINGKATKAN 
CITRA PERUSAHAAN." Jurnal

Ekonomi Integra 3, no. 1 (May 28,

2018): 001.

https://doi.org/10.51195/iga.v3i1.1

02 .

Ryan, Brigitte-Jane, April Jhonson, Strange

Amanda, and Yonovitz A. "The

'Hearing Aid Effect' in Northern

Territory Indigenous Australian

Children as Perceived by Their

Peers." Australian and New Zealand

Journal of Audiology 28, no. 2 (2006):

55-74.

https://search.informit.org/doi/10.3

316/INFORMIT.813719894564356.

Sugiyono. Metode Penelitian Pendidikan

(Pendekatan Kuantitatif, Kualitatif,

Dan R\&D). Bandung: Alfabeta, 2013.

Sukarnoputri, Megawati (presiden

Republik Indonesia). Undang-Undang

Nomor 20 Tahun 2003 Tentang

Sistem Pendidikan Nasional, Pub. L.

No. UU No 2 Tahun 2003 (2003).

Sulfemi, Wahyu. Manajemen Pendidikan

Berbasis Multi Budaya. Bogor: STKIP

Muhammadiyah Bogor, 2019.

Triwiyanto, Teguh. Manajemen Kurikulum Dan Pembelajaran. Jakarta: Bumi

Aksara, 2015.

Triyanto, Dwi. "Pelaksanaan Corporate

Social Responsibility (CSR) Di Bidang

Pendidikan PT. Hino Motors Sales

Indonesia (PT.HMSI)." Universitas

Negeri Yogyakarta, 2013.

Untung, Hendrik Budi. Corporate Social Responsibility (CSR). Jakarta: Sinar Grafika, 2007. 
182 | ibriez | Jurnal Kependidikan Dasar | Vol 5 No 2 Tahun 2020 